BMC

Infectious Diseases

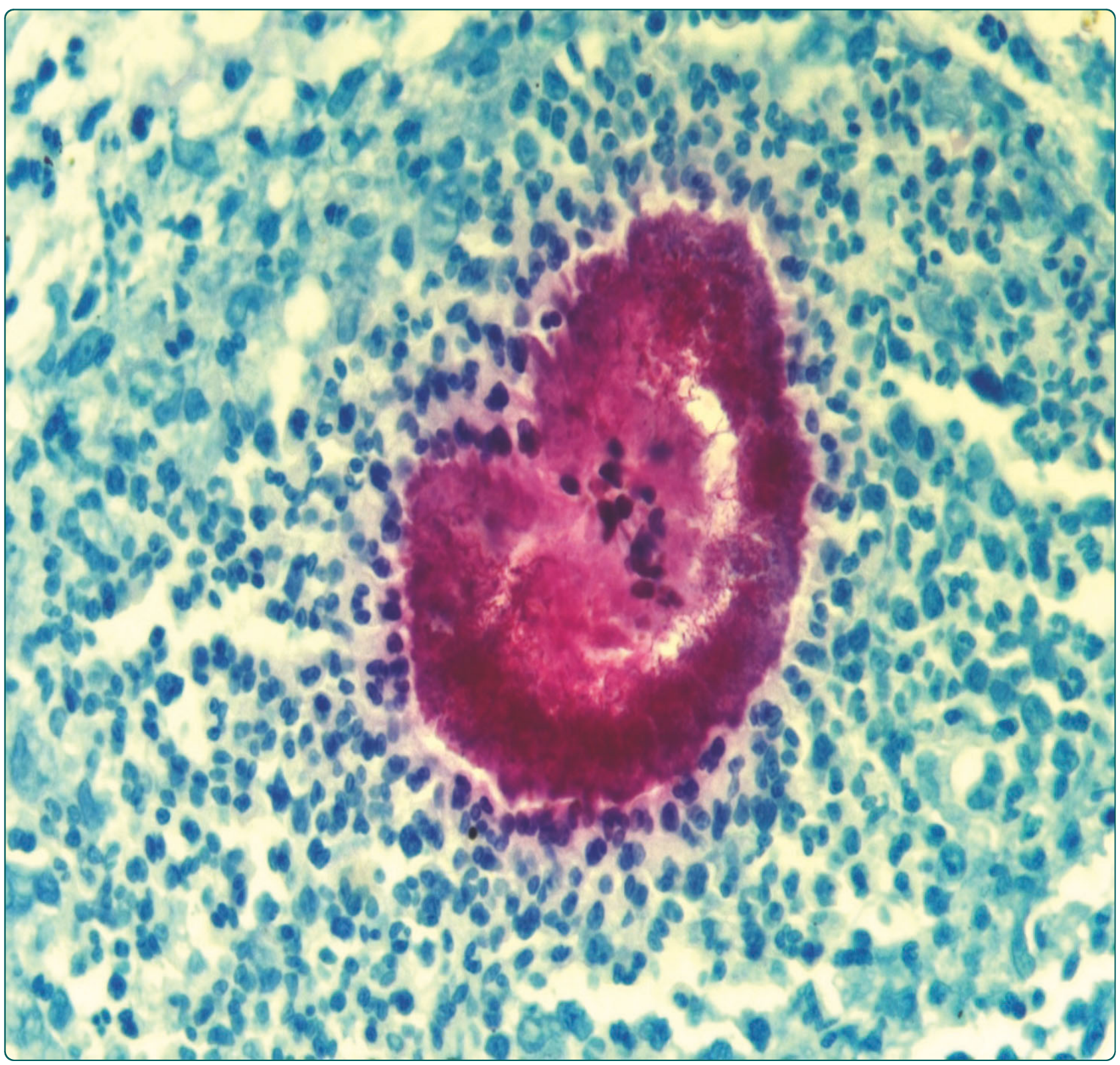

\title{
Decrease of virulence for BALB/c mice produced by continuous subculturing of Nocardia brasiliensis
}

Almaguer-Chávez et al. 


\title{
Decrease of virulence for BALB/c mice produced by continuous subculturing of Nocardia brasiliensis
}

\author{
Janeth A Almaguer-Chávez', Oliverio Welsh', Hector G Lozano-Garza², Salvador Said-Fernández², \\ Víktor J Romero-Díaz ${ }^{3}$, Jorge Ocampo-Candiani ${ }^{1}$ and Lucio Vera-Cabrera ${ }^{1 *}$
}

\begin{abstract}
Background: Subculturing has been extensively used to attenuate human pathogens. In this work we studied the effect of continuous subculturing of Nocardia brasiliensis HUJEG-1 on virulence in a murine model.

Methods: Nocardia brasiliensis HUJEG-1 was subcultured up to 130 times on brain heart infusion over four years. $\mathrm{BALB} / \mathrm{c}$ mice were inoculated in the right foot pad with the bacteria subcultured $0,40,80,100$ and 130 times $\left(T_{0}\right.$, $T_{40}, T_{80} T_{100}$ and $\left.T_{130}\right)$. The induction of resistance was tested by using $T_{130}$ to inoculate a group of mice followed by challenge with T0 12 weeks later. Biopsies were taken from the newly infected foot-pad and immunostained with antibodies against CD4, CD8 and CD14 in order to analyze the in situ immunological changes.
\end{abstract}

Results: When using $T_{40}, T_{80} T_{100}$ and $T_{130}$ as inoculums we observed lesions in 10, 5, 0 and 0 percent of the animals, respectively, at the end of 12 weeks. In contrast, their controls produced mycetoma in 80, 80, 70 and $60 \%$ of the inoculated animals. When studying the protection of $\mathrm{T}_{130}$, we observed a partial resistance to the infection. Immunostaining revealed an intense CD4+ lymphocytic and macrophage infiltrate in healing lesions.

Conclusions: After 130 in vitro passages of $\mathrm{N}$. brasiliensis HUJEG-1 a severe decrease in its virulence was observed. Immunization of BALB/C mice, with these attenuated cells, produced a state of partial resistance to infection with the non-subcultured isolate.

Keywords: Mycetoma, Nocardia, attenuation

\section{Background}

Mycetoma in Mexico is mainly caused by actinomycetes with Nocardia brasiliensis being predominantly isolated (86.6\% of the cases) together with Actinomadura madurae (9.6\% of the cases)[1]. In the state of Nuevo León, in northeast Mexico, where Monterrey is located, N. brasiliensis is isolated in $96 \%$ of cases [1]. Nocardia brasiliensis is a normal inhabitant of soil and from there it is inoculated by minor trauma with thorns or wood splinters. In humans, the disease is characterized by the production of extensive microabscesses surrounded by granulomatous tissue production. Its pathogenic mechanisms include the production of several proteases

\footnotetext{
* Correspondence: luvera_99@yahoo.com

'Servicio de Dermatología, Hospital Universitario "José E. González",

Monterrey, N.L., 64460 México Full list of author information is available at the end of the article
}

that might be involved in tissue destruction [2,3]. The production of an immune cellular response seems to be essential in order to stop infection [4]. However, it has also been claimed that the humoral immune response, particularly IgM subtype antibodies, plays an important role in resistance to infection [5].

Subculturing has been extensively used to attenuate human pathogens. The clearest example is the bacillus of Calmette and Guérin (BCG) which is a Mycobacterium bovis attenuated by continuous subculturing on potato-bile medium [6]. Avirulent BCG was produced after 230 serial passages of $M$. bovis and it is utilized to prevent extensive forms of tuberculosis. The mechanisms involved in its avirulence were obscure until recently when by sequencing the complete BCG chromosome, deletions of DNA stretches of up to $10-\mathrm{kb}$ (designated as RD, regions of difference) were observed
C Biomed Central 
[7]. The reconstitution of some of these genes restores most of the virulence of $M$. bovis BCG [8].

In the present work we studied if changes in virulence of Nocardia brasiliensis HUJEG-1 occurred by subculturing this microorganism 130 times. We also studied the ability of the non-virulent $N$. brasiliensis to induce resistance to the infection with the non-subcultured microorganism.

\section{Methods}

\section{Subculture method}

$N$. brasiliensis HUJEG-1 was used for these experiments; it has been utilized in previous assays [5,9]. Bacterial cultures obtained from mouse lesions were kept frozen at $-70^{\circ} \mathrm{C}$ in $20 \%$ skim milk. From these stocks, bacteria were grown on Sabouraud agar at $30^{\circ} \mathrm{C}$ for 4 to 7 days; then a single colony was placed in a $7 \mathrm{~mL}$ sterile Eveljham-Potter device. We added $2.5 \mathrm{~mL}$ of sterile saline and the bacterial mass was ground to obtain a homogeneous suspension and turbidity adjusted to McFarland's tube No 1 . With this suspension $(0.1 \mathrm{~mL})$ we inoculated a 125 $\mathrm{ml}$ Erlenmeyer flask containing $33 \mathrm{ml}$ of previously sterilized liquid medium Brain Heart Infusion (BHI). It was incubated with constant agitation at $110 \mathrm{rpm}$, at $37^{\circ} \mathrm{C}$. After $72 \mathrm{~h}$ the bacterial mass was harvested by centrifugation at 2,500 rpm for 3 minutes, washed, and ground as above. A new Erlenmeyer flask was inoculated with 0.1 $\mathrm{ml}$ of this suspension. These steps were repeated until reaching 130 subcultures $\left(\mathrm{T}_{130}\right)$. Samples were taken every 10 passages and kept frozen at $-70^{\circ} \mathrm{C}$, including $\mathrm{T} 0$. The entire process took about four years.

\section{Experimental mycetoma in a murine model}

Cultures were obtained from the aliquots stored in the deep freezer of passages 40, 80, 100 and $130\left(\mathrm{~T}_{40}, \mathrm{~T}_{80}\right.$, $\mathrm{T}_{100}$ and $\mathrm{T}_{130}$ respectively), as well as T0. The inoculums were prepared using a previously published technique [9], and adjusted to $20 \mathrm{mg}$ (wet weight) of Nocardia brasiliensis in $50 \mu \mathrm{L}$ of saline solution. Female BALB/c mice, 8-12 weeks-old were injected with $50 \mu \mathrm{l}$ of the nocardial suspension in the right footpad and the development of lesions was scored from 0 (for no inflammatory changes) to $4+$ (extension of the lesions beyond the ankle of the animal with extensive production of inflammation and abscesses) as previously described [9]. The thickness of each lesion was measured with a caliper every week for 12 weeks. The study was approved by the Comité Local de Investigación en Salud No. 1908, Centro de Investigación Biomédica del Noreste, IMSS, and the animal handling was done according to our institutions' guidelines.

\section{Induction of infection resistance in a murine model}

In order to study if infection with subcultured N. brasiliensis produced a state of immune resistance we inoculated a group of animals with $N$. brasiliensis subcultured 130 times in the right foot pad. After 12 weeks the left footpad was inoculated with the non-subcultured bacteria (T0). As a control we inoculated a group of animals of the same age with the non-subcultured isolate in the right footpad. In all cases the development of lesions was scored and measured as described above.

\section{Histopathological analysis comparing $\mathrm{T}_{0}$ and $\mathrm{T}_{130}$ strains}

For histopathological evaluation of the infection process we obtained biopsies of the inoculated footpad on weeks $1,3,5,7,9$ and 12 post-inoculation in both groups: the $\mathrm{T}_{130}$ re-inoculated group and the control. Biopsies were stored in $4 \%$ formalin for further processing and staining with H\&E, Kinyoun, and PAS. To identify the subsets of the inflammatory cells, the tissue samples were stained with antibodies against CD4 (helper T cells), CD8 (suppressor/cytotoxic T cells) and CD14 (monocytes). Briefly, sections from affected feet destined for immunohistochemistry were deparaffined, rehydrated and subjected to a sequence of incubation steps starting with sodium citrate $(0.01 \mathrm{M})$ for epitope recuperation. After blocking endogenous peroxidase activity with $1 \%$ hydrogen peroxide in methanol, sections were incubated in a humidity chamber during $18 \mathrm{~h}$ at $4^{\circ} \mathrm{C}$ with polyclonal anti-CD4, anti-CD8 and anti-CD14 (Dako Corp., Carpinteria, CA) diluted 1:200 in PBS. Following rinses in PBS, sections were incubated for $20 \mathrm{~min}$ at room temperature with biotinylated goat anti-rabbit antibody, and diluted 1:500 in PBS. This was followed by rinses in PBS and 20 min humidity chamber incubation in streptavidin-biotin. Peroxidase activity was visualized by incubating the sections with 3,3',-diaminobenzidine and counterstaining with hematoxilin.

\section{Statistical analysis}

The statistical analysis was performed with Statgraphics under the heading of The StatAdvisor and also with SPSS, Sigma Plot and Excel 2007. For comparison between groups an ANOVA analysis was conducted and as an alternative a Kruskal-Wallis test was applied. A $P$ $<0.05$ was considered statistically significant.

\section{Results}

\section{Effect of subculture on Nocardia brasiliensis HUJEG-1 virulence}

In Figure 1 we show the evolution of the natural infection in mice when inoculating the bacteria subcultured for 40 and 80 passages compared with the control $\left(\mathrm{T}_{0}\right)$. In the animals inoculated with T0 there is an initial inflammation due to an intense antigenic stimulation produced by the inoculum, followed by a decrease in the thickness of the footpad. Mycetomas appear after 56 weeks after infection. Twelve weeks after inoculation 



Figure 1 Development of lesions of mice infected with $\mathbf{T}_{\mathbf{4 0}}$, and $\mathbf{T}_{\mathbf{8 0}}$. Mice were infected with $20 \mathrm{mg}$ (wet weight) of bacterial fragments from $T_{40}$ (left) and $T_{80}$ (right). The footpad thickness was measured weekly; each point represents the mean of 20 animals and bars represent the standard deviation. As a control we inoculated a group of animals with T0 (open circles). When analyzed with the ANOVA test, a significantly difference was observed with regard to the control at 12 weeks post inoculation $(\boldsymbol{P}<0.001)$ in both cases.

there is an intense increase in the footpad size characterized by the presence of abscesses and fistulae.

When inoculated with the subcultured $N$. brasiliensis strains a different behavior was observed. After the initial inflammatory response the mean thickness of the footpad decreased significantly after five weeks postinoculation in all cases. The formation of mycetoma lesions (more than + ) at week 12, was observed in 10, 5 , 0 and 0 percent of the animals inoculated with $T_{40}, T_{80}$, $\mathrm{T}_{100}$ and $\mathrm{T}_{130}$ respectively (Table 1 ). Their controls produced mycetoma in $80,80,70$ and $60 \%$ of the inoculated animals. At week 12, the development of lesions in the groups inoculated with the subcultured isolate was compared with its own control (inoculated with T0), and analyzed with the ANOVA test. A $P<0.001$ was observed in all cases.

\section{Induction of infection resistance in a murine model}

The animals inoculated with $N$. brasiliensis subcultured 130 times produced no lesions until 12 weeks after inoculation $(P<0.001)$. At the end of 12 weeks, these

Table 1 Production of mycetoma lesions in BALB/c mice infected with the subcultured N.brasiliensis HUJEG-1 isolate

\begin{tabular}{lllll}
\hline \multirow{4}{*}{ Development of lesions } & Inoculum utilized & & \\
\cline { 2 - 5 } & T40 & T80 & T100 & T130 \\
\hline $0+$ & $18 / 20$ & $18 / 20$ & $20 / 20$ & $28 / 30$ \\
$1+$ & $0 / 20$ & $0 / 20$ & $0 / 20$ & $0 / 30$ \\
$2+$ & $2 / 20$ & $0 / 20$ & $0 / 20$ & $0 / 30$ \\
$3+$ & $0 / 20$ & $1 / 20$ & $0 / 20$ & $0 / 30$ \\
$4+$ & $0 / 20$ & $0 / 20$ & $0 / 20$ & $0 / 30$ \\
\hline
\end{tabular}

animals were challenged with the non-subcultured isolate in the left footpad (Figure 2). The natural evolution was similar in the first five weeks after inoculation with the non-subcultured isolate, but subsequently, we observed a decrease in the development of lesions as compared to their respective controls $(P=0.021)(P$ value determined by a variance test ANOVA).

\section{Histological study of the lesions}

In mice inoculated with the non-subcultured $N$. brasiliensis we observed abundant polymorphonuclear cells (PMN) surrounding the $N$. brasiliensis fragments inoculated (not yet constituted in grains) after 1 week of inoculation (Figure 3). Two weeks later, grains were observed surrounded by PMN and fibrosis was visible while at the periphery a layer made up of abundant foamy macrophages was evident. Seven weeks postinoculation abundant grains and microabscesses contained in concentric fibrotic walls were observed. And at the 12 weeks of inoculation gigantic foamy cells were present around the abscesses with grains floating in a huge abscess composed of PMN and necrotic cells. Macroscopically it was assigned as a $4+$ lesion.

The animals inoculated with $\mathrm{T}_{130}$ and re-inoculated with T0 showed an initial PMN infiltrate around the inoculum's fragment (Figure 4). Three weeks post-infection, micro abscesses containing the grains or inoculum fragments surrounded by a layer of foamy macrophages were present. At week five, microabcessess were formed with smaller amounts of foamy cells than in those in animals inoculated with $\mathrm{T}_{0}$ and grains in different stages of destruction were observed. A strong mononuclear infiltrate in the periphery of the microabscesses amongst 



Figure 2 Evolution of mycetoma lesions in animals inoculated with $\mathrm{T}_{130}$ (left) and re-inoculated with the T0 (right). Each point represents the mean of 30 animals; bars represent the standard deviation. An equal group of animals was inoculated with T0 (open circles). At twelve weeks after infection statistically significant differences were observed in both cases $(\boldsymbol{P}<0.001$ and $\boldsymbol{P}=0.021)$.

the collagen fibers was evident. After five weeks, there was a decrease in the number of animals with lesions (Figure 2). Biopsies taken from animals presenting lesions at 12 weeks showed abundant grains in microabscesses encapsulated in fibrotic walls.

\section{Immunostaining of the lesions}

In Table 2, the results of the immunostained biopsies are shown. In the animals inoculated with the non-subcultured isolate, we observed few CD8+ T lymphocytes, mostly situated around microabscesses, among the fibrosis; macrophages (CD14+ cells) were rarely seen. CD4+ $\mathrm{T}$ lymphocytes were observed more numerous. In heavily infected mice (12 weeks after infection), there were few lymphocytes and macrophages, perhaps due to the fact that most of the lesions were composed of abscesses.

In the animals inoculated with $\mathrm{T}_{130}$ and then challenged with the non-subcultured bacteria a different pattern emerged. CD8+T lymphocytes were rarely seen (Table 2) in all samples analyzed, while CD4+ lymphocytes were much more numerous after 5 weeks of inoculation (Figure 5). At this time clinical lesions decrease in size and most animals started to heal. Macrophages (CD14+ cells) were observed very abundantly in clusters from the fifth week in the scarred areas of the lesions, constituting most of the cells present (Figure 5).

\section{Discussion}

Five weeks after infection the lesions started to heal in the animals inoculated with $\mathrm{T}_{130}$ and re-inoculated with T0. At this time the lesions were microscopically characterized by the presence of hollow and semidestroyed grains as well as by the presence of an intense mononuclear infiltrate. These microscopical features are similar to those observed in Lewis rats infected with $N$. brasiliensis [10]. These animals are naturally resistant to the infection even when using high amounts of bacteria. They present an initial inflammatory reaction, but from this point the lesions start to heal spontaneously; in the microscope, thin-walled, semi-destroyed grains are observed. This suggests that immunization with the attenuated cells $\left(\mathrm{T}_{130}\right)$ can induce an immune state of resistance, although it is not complete. It will be important to assay re-immunizations with the whole bacteria or crude extracts to determine if the level of resistance can be increased.

The presence of small amounts of lymphocytes and macrophages in biopsy tissue of human cases of actinomycetoma has been reported $[11,12]$. They are present in low numbers and are situated at the periphery of the microabscesses; similar findings were observed in this work in mice infected with $\mathrm{T}_{0}$. In leprosy, two patterns of in situ localization of $\mathrm{T}$ lymphocytes subsets have been described: in tuberculoid lesions CD8+ (OKT8+) cells are found around the granulomata, and CD4+ (OKT4+) cells are distributed throughout the granuloma [13]. In lepromatous patients both subsets are distributed throughout the granuloma with no predilection for the periphery. The organization of $\mathrm{T}$ lymphocyte subsets in tuberculoid leprosy reflects an effective immune response. In actinomycetoma, there are not true granulomas, instead the microorganisms are contained inside microabscesses surrounded by a layer of foam laden macrophages. These microscopic features have been 


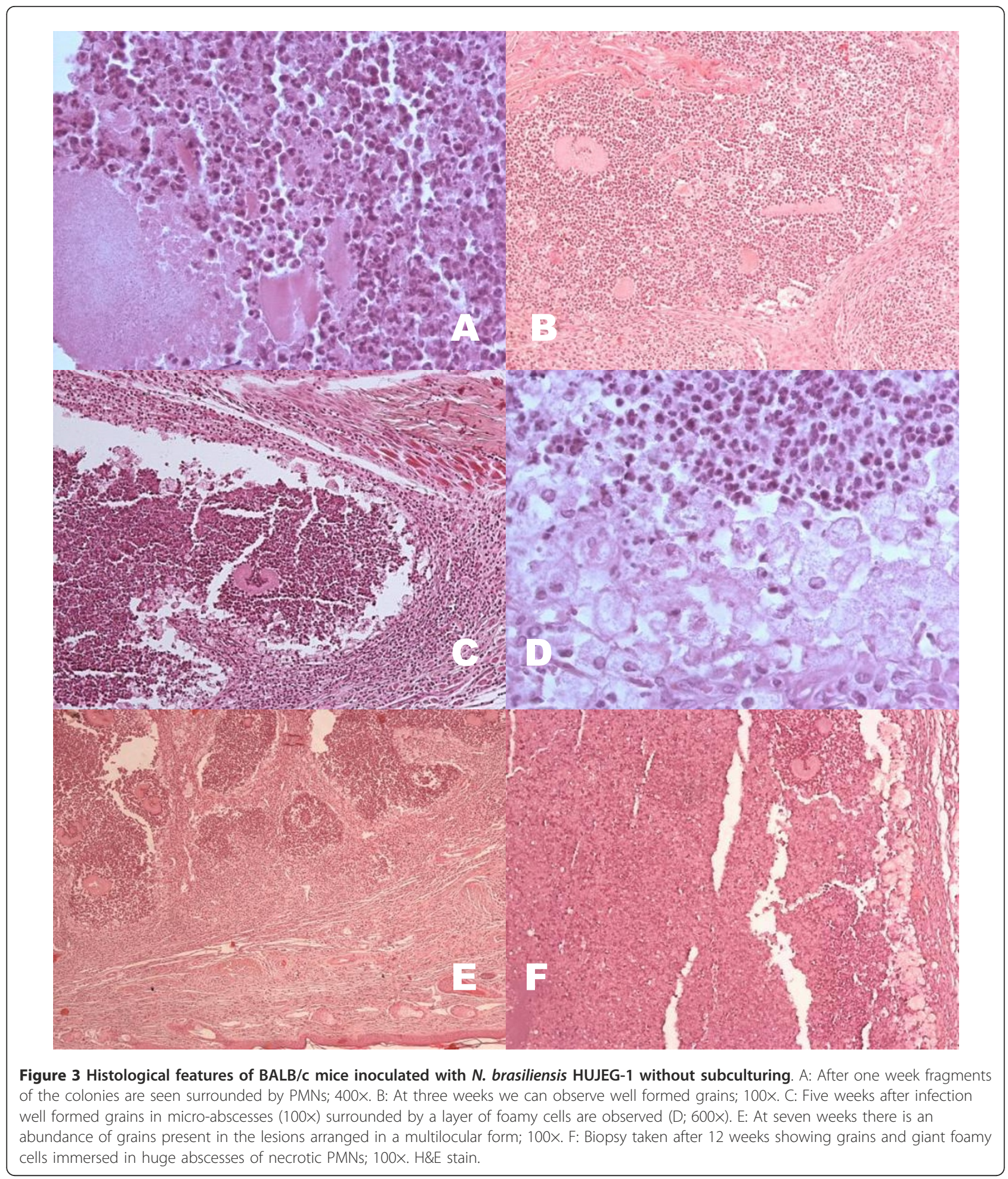

described before as " $N$. brasiliensis lesions" which are different of those presented by "N. asteroides" [14]. In the case of mice immunized with $\mathrm{T}_{130}$ and then challenged with T0 we observed an increase in CD4+ lymphocytes as well as an abundant infiltrate of macrophages (CD14+ cells) five weeks after immunization. Mononuclear cells were always located in clusters outside the microabscesses in the scar tissue. It appears that this remarkable increase in the number of macrophages is responsible for the elimination of Nocardia 


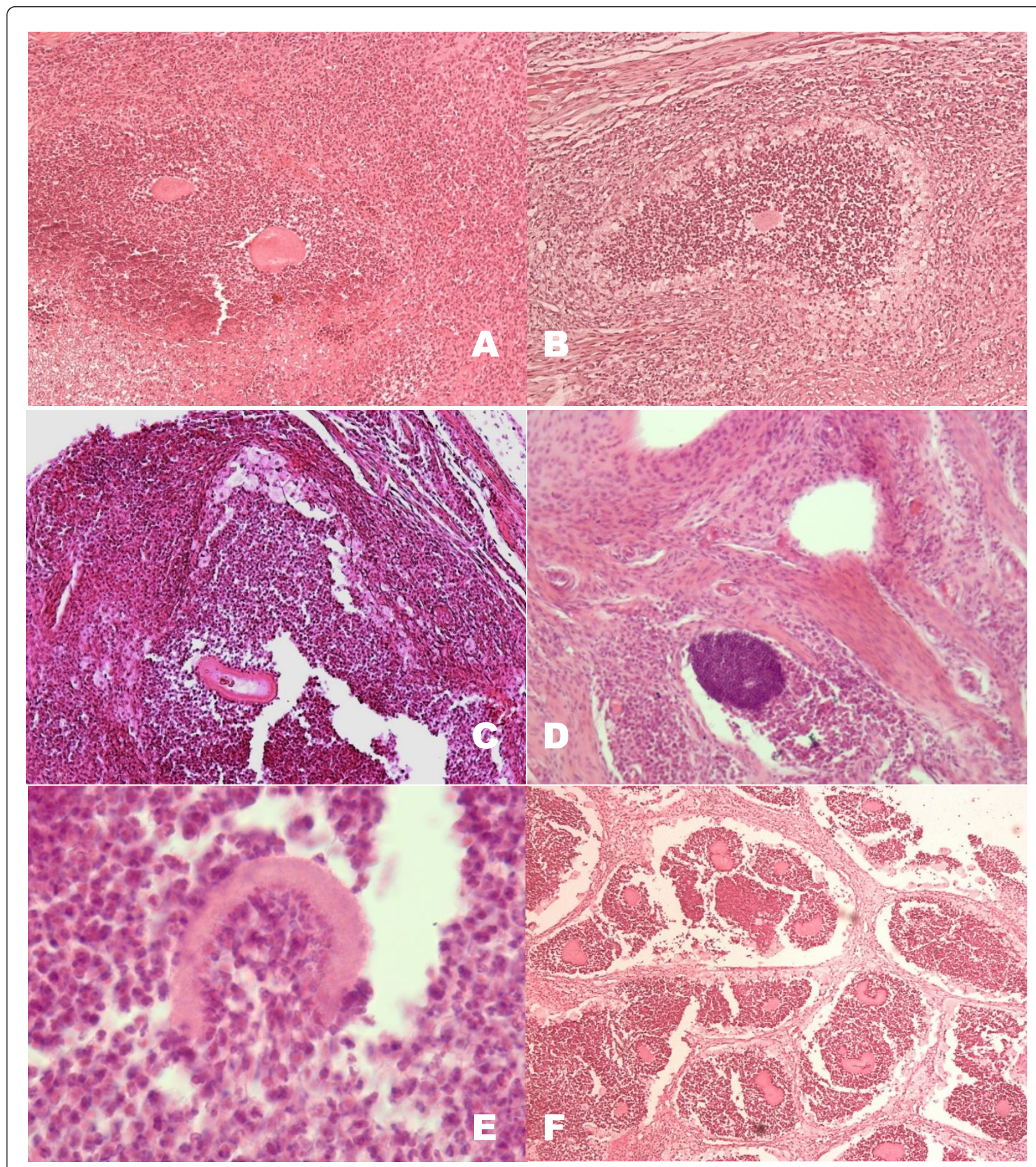

Figure 4 Histological features of BALB/c mice inoculated with $N$. brasiliensis HUJEG-1 T130 and re-inoculated with T0. A and B: In the first 3 weeks findings are similar to those of the animals inoculated with $T_{0} ; 100 \times$. C, and D: At five weeks an intense mononuclear infiltrate was observed (100X), with thin walled grains and abundant PMNs attached to them ( $E ; 600 \times)$. F: At twelve weeks, some animals presented lesions with grains in microabscesses surrounded by fibrotic walls; 100x. H\&E stain. 
Table 2 Results of immunostaining biopsies of lesions with antibodies against CD4, CD8 and CD14.

\begin{tabular}{lllllll}
\hline Weeks after Reaction to Inoculation antibody against: \\
\cline { 2 - 7 } & CD4 & \multicolumn{5}{c}{ CD8 } \\
\cline { 2 - 7 } & $\mathrm{T}_{0}$ & $\mathrm{~T}_{130}$ & $\mathrm{~T}_{0}$ & $\mathrm{~T}_{130}$ & $\mathrm{~T}_{0}$ & $\mathrm{~T}_{130}$ \\
1 & $(-)$ & \pm & $(-)$ & $(-)$ & $(-)$ & $(-)$ \\
3 & ++ & $(-)$ & + & $( \pm)$ & $( \pm)$ & $( \pm)$ \\
5 & ++ & +++ & + & $( \pm)$ & + & ++++ \\
12 & \pm & ++ & \pm & $( \pm)$ & $( \pm)$ & +++ \\
\hline
\end{tabular}

and consequent healing of the lesions in our experiments. The identification of the antigens of $N$. brasiliensis which elicits this cellular immune response, as well as the immune mechanisms (cytokines and cells) involved in the destruction of the grains, will help to provide a better understanding of the resistance mechanisms to $N$. brasiliensis.

Studies on bacterial evolution have permitted the analysis of changes in the genome produced by adaptation to a particular medium or niche. In Escherichia coli it has been observed that mutations, deletions, IS insertions, duplications and inversions in the chromosome appear in as short as in 2000 generations [15] and gene changes increase in a linear form until 20,000 generations producing the loss of about $1.2 \%$ of the original chromosome (during a total of 20 years of subculturing). Although it is a large amount of deleted, DNA most of the mutations observed were synonymous (without sense), not affecting the biological properties of the bacterium. In our case it seems that Nocardia needs only a few generations to produce changes in its virulence, since after 40 subcultures we observed a remarkable

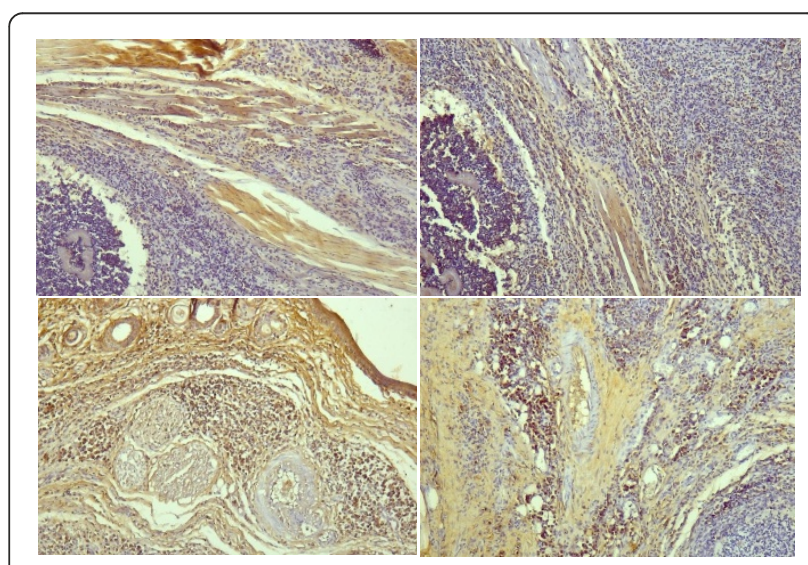

Figure 5 Immunostaining of biopsies of lesions at five weeks postinfection. Top: Mouse inoculated with the non-subcultured isolate showing positive cells for anti-CD4 (left) and for anti-CD14 (right); 100x. Bottom: Foot-pad biopsy of mouse inoculated with $\mathrm{T}_{130}$. CD4+ (left) and CD14+ (right) T-cell lymphocytes are seen abundantly surrounding the microabscesses among the scarring tissue; $(100 \times)$. difference in virulence. In Burkholderia cenocepacia as little as 500 generations made this bacterium unable to kill the nematode Caenorhabditis elegans [16]. In that work 1000 generations took about 152 daily subcultures. Given the longer generation time of Nocardia it took about 4 years to achieve 130 subcultures. It is difficult to calculate the exact number of generations since Nocardia brasiliensis divides by producing filaments rather than by binary fission. It will be necessary to design an experiment to overcome this problem and determine the number of generations in order to compare our results with other experiments in microbial evolution.

In the case of $M$. bovis, a phylogenetically related organism, it took about 230 subcultures in potato-ox bile liquid medium to decrease its virulence for several mammals, including calves, horses, and man [6]. BCG attenuation has been explained by the loss of large DNA stretches (known as the regions of difference, RD) [7], with the most important being RD1 which includes ORF's coding for proteins ESAT-6 and CFP10. In the case of $N$. brasiliensis, we observed a significant decrease in virulence, however since we do not yet have the $N$. brasiliensis genome sequence, we can not determine the genetic changes responsible for the decrease in virulence. DNA sequence analysis of the complete genome of $N$. brasiliensis will allow us to determine the genes involved in Nocardia brasiliensis virulence.

\section{Conclusion}

In conclusion, we observed a remarkable decrease in the virulence of Nocardia brasiliensis HUJEG-1 after subculturing it 130 times in vitro, compared to the parent strain. This can be an excellent model to study the immunological mechanisms involved in resistance in mycetoma, since a previous inoculation with the attenuated $N$. brasiliensis provides protection against the infection with the parent strain or T0.

\footnotetext{
Acknowledgements

We would like to thank Dr. Sergio Lozano and Dr. Michael Pucci for reviewing the English style of the manuscript. This work partially fulfills the requirement for the degree of Doctor in Medicine (Facultad de Medicina, Universidad Autónoma de Nuevo León) of the first author (J.A. A-Ch.). This work was supported by PAICYT grant SA 261-09.
}

\section{Author details}

'Servicio de Dermatología, Hospital Universitario "José E. González", Monterrey, N.L., 64460 México. ${ }^{2}$ Centro de Investigación Biomédica del Noreste, IMSS, Monterrey, N.L., 64720, México. ${ }^{3}$ Departamento de Histología, Facultad de Medicina, UANL., Monterrey, N.L., 64460 México.

\section{Authors' contributions}

LV-C and JAA-Ch. were responsible for conception and design of the study, conduct of analysis, interpretation of data, and drafting and revision of the manuscript; JO-C and OW were involved in design of the study, conduct of analysis, interpretation of data and critical revision of the manuscript; $\mathrm{HG}-\mathrm{L}$ and SS in design of the study, interpretation of data, and critical revision of 
the manuscript. VJR-D helped with the immunostaining techniques. All authors read and approved the final manuscript

\section{Competing interests}

The authors declare that they have no competing interests.

Received: 7 March 2011 Accepted: 26 October 2011

Published: 26 October 2011

\section{References}

1. López-Martínez R, Méndez-Tovar L, Lavalle P, Welsh O, Saul A, MacotelaRuiz E: Epidemiología del micetoma en México: estudio de 2105 casos. Gac Med Mex 1992, 128(4):477-481.

2. Licón-Trillo A, Castro-Corona MA, Salinas-Carmona MC: Immunogenicity and biophysical properties of a Nocardia brasiliensis protease involved in pathogenesis of mycetoma. FEMS Immunol Med Microbiol 2003, 37(1):37-44.

3. Zlotnik H, Schramm VL, Buckley HR: Purification and partial characterization of a Nocardia brasiliensis extracellular protease. Bacteriol 1984, 157(2):627-631.

4. Folb PI, Timme A, Horowitz A: Nocardia infections in congenitally athymic (nude) mice and in other inbred mouse strains. Infect Immun 1977, 18(2):459-466.

5. Gonzalez-Suarez ML, Salinas-Carmona MC, Pérez-Rivera I: IgM but not IgG monoclonal anti-Nocardia brasiliensis antibodies confer protection against experimental actinomycetoma in BALB/c mice. FEMS Immunol Med Microbiol 2009, 57(1):17-24.

6. Calmette A: La Vaccination preventive contre la tuberculose par le "BCG". Masson et Cie, Editeurs Libraires de L'Academie de Medecine 120, Boulevard saint-Germain, Paris; 1927.

7. Philipp WJ, Nair S, Guglielmi G, Lagranderie M, Gicquel B, Cole ST: Physical mapping of Mycobacterium bovis BCG pasteur reveals differences from the genome map of Mycobacterium tuberculosis H37Rv and from $M$. bovis. Microbiology 1996, 142(Pf11):3135-3145.

8. Pym AS, Brodin P, Brosch R, Huerre M, Cole ST: Loss of RD1 contributed to the attenuation of the live tuberculosis vaccines Mycobacterium bovis BCG and Mycobacterium microti. Mol Microbiol 2002, 46(3):709-717.

9. Espinoza-González NA, Welsh O, de Torres NW, Cavazos-Rocha N, OcampoCandiani J, Said-Fernandez S, Lozano-Garza HG, Choi SH, Vera-Cabrera L: Efficacy of DA-7218, a new oxazolidinone prodrug, in the treatment of experimental actinomycetoma produced by Nocardia brasiliensis. Molecules 2008, 13(1):31-40.

10. Vera-Cabrera L, Rodriguez-Quintanilla MA, Boiron P, Salinas-Carmona MC, Welsh 0: Experimental mycetoma by Nocardia brasiliensis in rats. Journal Mycol Méd 1998, 8(4):183-187.

11. Guimarães CC, Castro LG, Sotto MN: Lymphocyte subsets, macrophages and Langerhans cells in actinomycetoma and eumycetoma tissue reaction. Acta Trop 2003, 87(3):377-384.

12. Palma-Ramos A, Castrillón-Rivera LE, Pizaña-Cureño A, Vega-Memije ME, López-Bárcenas AP, Arenas-Guzmán R, Padilla-Desgarennes MC: Subpoblaciones de linfocitos T en el micetoma. Derm Rev Mex 2007, 51(6):212-218.

13. Modlin RL, Hofman FM, Meyer PR, Sharma OP, Taylor CR, Rea TH: In situ demonstration of $\mathrm{T}$ lymphocyte subsets in granulomatous inflammation: leprosy, rhinoscleroma and sarcoidosis. Clin Exp Immunol 1983, 51(3):430-438.

14. Folb PI, Jaffe R, Altmann G: Nocardia asteroides and Nocardia brasiliensis infections in mice. Infect Immun 1976, 13(5):1490-1496.

15. Barrick JE, Yu DS, Yoon SH, Jeong H, Oh TK, Schneider D, Lenski RE, Kim JF: Genome evolution and adaptation in a long-term experiment with Escherichia coli. Nature 2009, 461(7268):1243-1247.

16. Ellis CN, Cooper VS: Experimental adaptation of Burkholderia cenocepacia to onion medium reduces host range. Appl Environ Microbiol 2010, 76(8):2387-2396

\section{Pre-publication history}

The pre-publication history for this paper can be accessed here:

http://www.biomedcentral.com/1471-2334/11/290/prepub doi:10.1186/1471-2334-11-290

Cite this article as: Almaguer-Chávez et al:: Decrease of virulence for BALB/c mice produced by continuous subculturing of Nocardia brasiliensis. BMC Infectious Diseases 2011 11:290.

\section{Submit your next manuscript to BioMed Central and take full advantage of:}

- Convenient online submission

- Thorough peer review

- No space constraints or color figure charges

- Immediate publication on acceptance

- Inclusion in PubMed, CAS, Scopus and Google Scholar

- Research which is freely available for redistribution

Submit your manuscript at www.biomedcentral.com/submit
Ciomed Central 